\title{
BMJ Open How do doctors in the Netherlands perceive the impact of disciplinary procedures and disclosure of disciplinary measures on their professional practice, health and career opportunities? A questionnaire among medical doctors who received a disciplinary measure
}

Berber S Laarman, ${ }^{1}$ Renée JR Bouwman, ${ }^{2}$ Anke JE de Veer, ${ }^{2}$ Michelle Hendriks, ${ }^{3}$ Roland D Friele ${ }^{2}$

To cite: Laarman BS, Bouwman RJR, de Veer AJE, et al. How do doctors in the Netherlands perceive the impact of disciplinary procedures and disclosure of disciplinary measures on their professional practice, health and career opportunities? A questionnaire among medical doctors who received a disciplinary measure. BMJ Open 2019;9:e023576. doi:10.1136/ bmjopen-2018-023576

- Prepublication history for this paper is available online. To view these files, please visit the journal online (http://dx.doi. org/10.1136/bmjopen-2018023576).

Received 13 April 2018

Revised 8 October 2018

Accepted 17 December 2018

Check for updates

(C) Author(s) (or their employer(s)) 2019. Re-use permitted under CC BY-NC. No commercial re-use. See rights and permissions. Published by BMJ.

For numbered affiliations see end of article.

Correspondence to Miss Berber S Laarman; b.s.laarman@vu.nl

\section{ABSTRACT}

Introduction Disciplinary procedures can have serious consequences for the health, personal life and professional functioning of doctors. Until recently, specific disciplinary measures (reprimands) were publicly disclosed in the Netherlands. The perceived additional impact of disclosing reprimands on the professional and personal life of doctors is unclear.

Methods All doctors who received a disciplinary measure from the Dutch Disciplinary Board between July 2012 and August 2016 were invited to partake in a 60 -item questionnaire concerning the respondents' characteristics, the complaint, experience with the procedure and perceived impact of the procedure on health and professional functioning as reported by doctors themselves. The response rate was $43 \%(n=210) .21 .4 \%$ received a reprimand (disclosed); the remainder received a warning (not disclosed). Differences between the two groups were calculated.

Results Respondents with a reprimand reported significantly more negative experiences and impact on health and work than respondents with a warning. $37.8 \%$ of the doctors said their health was very good. A small percentage reported moderate-to-severe depressive complaints (3.6\%), moderate-to-severe anxiety disorder (2\%) or indications of burnout (10.8\%). The majority reported changes in their professional practices associated with 'defensive medicine', such as doing more supplementary research (41\%) and complying more with patients' wishes (35\%).

Conclusion The Dutch disciplinary procedure has strong negative side effects, that disclosing measures seems to increase. Dutch disciplinary law aims to contribute to the quality of professional practice. A safe environment is a basic condition for quality improvement and therefore, disclosure of disciplinary measures should be carefully

\section{Strengths and limitations of this study}

- This study assesses how doctors perceive the impact of a disciplinary measure on the doctor's (a) health (in general and the impact of the procedure on health at moment of filling out questionnaire and directly after the procedure), (b) professional functioning, (c) business/financial consequences and (d) career opportunities, beyond the impact of the measure itself.

- This is a valuable addition to the existing body of research.

- The study sample was not large.

- The two groups of measures (warning and reprimand) may not be comparable because of the context and nature of the complaint and the related culpability and judgement of the disciplinary court.

The results are self-reported by the respondents.

considered. Disclosure of disciplinary measures has always been controversial and the results of this study has rekindled this debate. Recently, a majority in the Dutch House of Representatives has voted against disclosure of reprimands, leaving disclosure of reprimands a discretion of the disciplinary board when deemed appropriate or necessary.

\section{INTRODUCTION}

The past few years have seen increasing awareness of the welfare of doctors after a patient safety incident. A growing body of literature describes doctors suffering from powerful feelings of guilt, incompetence or inadequacy following a patient safety 
incident. The severity of these consequences has even earned doctors the term 'second victim', meaning 'a healthcare provider involved in an unanticipated adverse patient event [...] who become[s] victimised in the sense that the provider is traumatised by the event'. ${ }^{1-9}$ Studies reveal that the prevalence of second victims of medical errors is high, ranging from $10.4 \%$ to $43.3 \%$ in various studies. ${ }^{34}$

Procedures that might follow a patient safety incident or a patient complaint can worsen this impact. Studies show that procedures related to medicine and law, such as complaints or disciplinary processes, often have a major impact on health, personal life and professional functioning, ${ }^{10-14}$ leading to concerns about the quality of healthcare these professionals provide. A second concern is the phenomenon of 'defensive medicine ${ }^{, 15-17}$ referring to the practice of performing additional and unnecessary diagnostic tests or the avoidance of high-risk medical treatments for patients in an effort to avoid complaints or claims. Whether fears of disciplinary consequences are justified or not, if professionals display defensive practices these can raise healthcare costs and may subject patients to unnecessary tests and processes. ${ }^{12} 18 \mathrm{~A}$ third concern is that the fear of legal consequences may compromise physicians' willingness to disclose medical errors. ${ }^{19} 20$

An interview study among 16 doctors in the Netherlands showed doctors experience a profound psychological and professional impact of the disciplinary process and imposed measures that follow a patient's complaint to disciplinary tribunal. ${ }^{13}$ Until recently, specific types of disciplinary measures (reprimands, fines and measures that restrict professionals from practising medicine) were disclosed in an online register and in regional newspapers with the aim of improving healthcare quality, providing patients with information about quality of healthcare and warning patients and employers for professionals who are restricted from practice (box 1). Warnings are not disclosed.

In this study, we assess how disciplined doctors experienced the disciplinary procedure, the related measures and their disclosure and the perceived impact on welfare and professional functioning. We focused on medical doctors with a complaint that was deemed valid by the disciplinary board and who were given a warning (which is not publicly disclosed) and doctors who were given a reprimand (which is publicly disclosed), then assessing whether differences can be observed between the two groups. We hypothesised reprimanded doctors would report a bigger impact than warned doctors, partly due to the disclosure of the reprimand. We realise that differences between the groups can be both resultant of the outcome (heavier measure) as of the disclosure of the measure, or can be mutually reinforcing as a reprimand can be experienced as a heavier measure precisely because it was disclosed.

\section{Box 1 Information about the Dutch disciplinary system}

The Dutch disciplinary system as set down in the Individual Healthcare Professions Act (BIG) is aimed at correcting the care providers' behaviour, improving healthcare quality and learning. Patients and other parties with a direct interest (the Dutch Healthcare Inspectorate, employers or, under certain conditions, colleagues) can file a complaint with the Medical Disciplinary Board. Even though the procedure places the professional conduct of individual doctors under scrutiny, the disciplinary procedures do not have the formal purpose of punishing doctors. The BIG Act sets out two disciplinary standards. The first refers to individual healthcare in neglecting a patient's need for care, such as incorrectly informing the patient, incorrect or delayed diagnosis or failure to perform a treatment. The second disciplinary norm refers to the general interest embodied in proper pursuit of the profession. This includes administrative actions, dealing with colleagues or actions in the media. The conduct of healthcare professionals assessed under disciplinary standard (1) is measured against the professional standard. The professional standard is composed of the state of the art of medical practice, construed inter alia out of relevant guidelines, protocols, scientific publications and case law by the disciplinary boards. ${ }^{40} 41$

If a complaint is judged valid, doctors can be disciplined with (in order of gravity of the measure) a warning, a reprimand, a monetary fine, a conditional or definite suspension, withdrawal of the right to perform certain treatments or the right to re-register (in cases where a professional voluntarily resigns from a register) or removal from the register. Professionals receive a warning when behaviour was not entirely correct, but not reprehensible. Professionals who acted in breach with the professional standard but who are still fit for unconditional practice receive a reprimand. In practice, the line between a warning and a reprimand can be vague.

From 1 July 2012 until 10 July 2018 besides the restrictive measures (conditional suspension, withdrawal of the right to perform certain processes, removal from the register), reprimands and fines imposed by the Medical Disciplinary Board are disclosed as well. The idea is that disclosure of the measures imposed can protect the public against dysfunctional care providers and provide them with information for making a better choice of healthcare professional. Furthermore, it would also help us learn from things that went wrong in healthcare. ${ }^{42} 43$

Although other countries such as Germany, the UK and the USA also have disciplinary systems where comparable measures can be imposed, there are also important differences. For instance, there are differences in definitions used (such as fitness to practice vs professional misconduct), the structures and levels of the bodies handling them and the likelihood of a formal judgement after a complaint has been received can vary greatly. ${ }^{44} 45$ These differences in procedural characteristics have to be taken into account when comparing research outcomes.

\section{AIM AND RESEARCH QUESTIONS}

The objective of this study is to describe the experience of medical doctors with and the perceived impact of a disciplinary procedure and a disciplinary measure. Research questions are:

1. What feelings did doctors experience during the disciplinary procedure?

2. How do doctors perceive the impact of a disciplinary measure on the doctor's (a) health (in general and the impact of the procedure on health at moment of filling out questionnaire and directly after the procedure), 
(b) professional functioning, (c) business/financial consequences and (d) career opportunities?

3. Are there differences between people who received a warning and those who received a reprimand in terms of the experiences and the perceived impact?

\section{METHODS}

\section{Study population and data collection}

This study focused on all medical doctors who received a warning or reprimand during the period July 2012 to August 2016. To give an indication of the numbers of disciplinary measures imposed annually, approximately 700 measures were imposed by a disciplinary board in the Netherlands in 2015. ${ }^{21}$

Doctors were enrolled in the study through the disciplinary boards. All doctors with a reprimand or warning received a letter in September 2016 inviting them to fill in a questionnaire online. Two reminder letters were sent to maximise the response. Privacy was considered very important given the sensitivity of the subject, so in close consultation with the disciplinary boards and the Ministry of Health we took the following measures:

- All letters were sent by the disciplinary board; the doctors remained anonymous to the researchers.

- A privacy policy was drawn up describing the process. This privacy policy was sent with the letter requesting participation in the study.

- All letters were sent in a plain white envelope without sender address, and the word 'confidential' was printed on the envelope.

- For privacy reasons, no response records were kept, so the two reminder letters were sent to all professionals. In order to create a homogenous study population with comparable contextual factors such as education, all care professionals other than medical doctors were removed from the dataset.

- The disciplinary boards received no information about which doctors did and did not respond and neither did the researchers.

\section{Questionnaire}

The questionnaire is based on insights from national and international literature. ${ }^{10} 132223$ The questionnaire concerned the following subjects:

- General characteristics: respondent's characteristics and occupation.

- Parameters of the complaint that led to the procedure.

- Feelings experienced during the disciplinary procedure (measured on a 10-point scale ('not at all' to 'very much').

- Self-reported general health ('very bad' to 'very good'), perceived impact of the disciplinary process on health (10-point scale from 'no impact' to a 'very large impact'), Patient Health Questionnaire (PHQ-9) for measuring depressive complaints, the Generalised Anxiety Disorder scale (GAD-7) and the shortened version of Maslach Burnout Inventory Test.
- Changes in professional functioning professionals consider due to the disciplinary process, business/ financial consequences and career opportunities after the disciplinary procedure.

To check the face validity of the questionnaire, we asked the members of an advisory committee of medical professionals, Disciplinary Board members, the Patient Federation of the Netherlands and the Ministry of Health, Welfare and Sports to review the questionnaire (in writing). Based on their reactions, the questionnaire has been adjusted. The questionnaire was then sent to 10 healthcare professionals (4 healthcare psychologists, 4 doctors, 1 nurse, 1 physiotherapist) registered under the BIG Act. They were asked if the questions were properly understandable and clearly formulated, whether the answer categories were correct, whether they thought any answer categories or questions were missing, whether it was easy to fill out and whether the questionnaire was logically structured. Their feedback was used to draw up the final version of the questionnaire.

\section{Patient and public involvement}

As described, patients were represented during the assessment of the questionnaire. Furthermore, part of the complaints were lodged by patients or their family, through which they are included in the study in an indirect way.

\section{Analyses}

The response rate was $43 \%(\mathrm{n}=210) ; 21.4 \%$ received a reprimand (disclosed), the remainder received a warning (not disclosed). The questionnaires of the following classes of respondents were removed from the data file:

- Respondents who indicated that they had not received a reprimand or warning $(n=37)$;

- Respondents who stated that the disciplinary process had not yet been completed $(n=5)$;

- Respondents who filled in less than half of the questions $(n=2)$;

- Respondents with an occupation other than medical doctors $(n=84)$.

\section{Calculating composite scores of outcome variables}

When determining the effects of the disciplinary measure on doctors' health, the following scores were calculated:

Depressive symptoms: scores on the PHQ-9 items ranged from 0 (not at all) to 3 (almost every day). We calculated a sum score for the respondents who filled in all the items. As in the study by Bourne et al, we considered respondents with a score of 10 or higher to be depressed. ${ }^{10}$

Anxiety disorders: scores on the GAD-7 items ranged from 0 (not at all) to 3 (almost every day). We calculated a sum score for the respondents who filled in all the items. As in the study by Bourne $e t$ al, we considered respondents with a score of 10 or above to be suffering from anxiety disorder. $^{10}$

Burnout: the scores on the shortened version of the Maslach Burnout Inventory Test ranged from 0 (never) 
to 6 (every day). We calculated an average score for the respondents who filled in three or more of the five items. We compared the results with the National Survey of Working Conditions benchmark (NEA), in which a large number of Dutch employees are asked about their organisation and content of labour, labour relations, working conditions and their health. As in the NEA, we considered respondents with a score of 3.20 or above to be suffering from burnout complaints. ${ }^{22}$

\section{Comparison of groups of doctors}

The responses of doctors with a reprimand and doctors with a warning were compared using analysis of variance (averages), $\mathrm{X}^{2}$ test and Fisher's exact test (with frequency distributions). We considered differences to be significant where they had a $p$ value of $<0.05$.

\section{Ethical considerations}

This study was based on questionnaires completed by doctors; no patients were involved. Participation in the study was voluntary. The questionnaire data was stored and analysed anonymously, in accordance with the Dutch Personal Data Protection Act (http://www.privacy.nl/ uploads/guide_for_controller_ministry_justice.pdf).

\section{RESULTS}

General characteristics of the study population and complaints process

The response rate for the questionnaire was $43 \%$. After exclusion of the respondents as described in the 'Methods' section, 210 doctors were left in the data file. Of these, $78.7 \%$ were male. The over-50 age groups are somewhat over-represented (together $75.2 \%$, table 1 ). In the total Dutch population of doctors in $2015,49.4 \%$ were male and $6.2 \%$ (data is only available for age 65 and older) were older than 65 years. ${ }^{24}$ In our study population, $38.4 \%$ were general practitioners, $48.2 \%$ medical specialists, $13.4 \%$ other. For more than one-third of the respondents, it was $>2$ years since they received their warning or reprimand (not in table). Of all respondents, $78.6 \%$ were given a warning and $21.4 \%$ a reprimand.

Table 1 Characteristics of the study population: doctors given a reprimand $(n=45)$ and doctors given a warning $(n=162-165)$

Reprimand, \% Warning, \% Total, \%

\begin{tabular}{lcrr}
\hline Age (years) & & & \\
\hline 39 or younger & 0 & 6.7 & 5.2 \\
$40-49$ & 15.6 & 20.6 & 19.5 \\
\hline $50-59$ & 42.2 & 37.0 & 38.1 \\
60 or older & 42.2 & 35.8 & 37.1 \\
\hline Male & 84.4 & 77.2 & 78.7 \\
\hline Female & 15.6 & 22.8 & 21.3 \\
\hline
\end{tabular}

Table 2 Feelings experienced during the disciplinary procedure, average on a scale from 0 to 10 (not at all to very much) $(n=191-207)^{\star}$

\begin{tabular}{llll}
\hline & Warning & Reprimand & P value \\
\hline Attacked & 6.8 & 8.2 & 0.0031 \\
Criminalised & 4.6 & 7.5 & 0.000 \\
Powerless & 5.9 & 7.5 & 0.0034 \\
Angry & 6.1 & 7.0 & 0.05 \\
Insecure & 4.8 & 5.6 & \\
Lonely & 4.2 & 5.3 & \\
Sad & 4.2 & 4.8 & \\
Scared & 3.3 & 4.0 & \\
Embarrassed & 3.2 & 4.3 & \\
Guilty & 2.3 & 2.7 & \\
Failed & 2.4 & 2.9 & \\
Relieved & 0.8 & 0.4 & \\
\hline
\end{tabular}

*Only significant differences are given.

\section{Experiences with the disciplinary procedure}

The most commonly experienced feeling among doctors during the procedure was that they felt under attack, and this significantly differed between doctors receiving a warning (average score 6.8) and a reprimand (average score 8.2). Other feelings experienced were feeling criminalised, feeling powerless or being angry. For all these items, significant differences were found for doctors receiving warnings and reprimands, with the latter group reporting higher scores (table 2). Only $22.6 \%$ of the doctors getting a warning and $4.4 \%$ of the doctors getting a reprimand were of the opinion that the judge had made a right judgement on the disciplinary complaint $(p=0.02)$ (not in table). This might not be surprising, but it is relevant as disciplinary procedures are supposed to be a learning experience.

\section{Health of disciplined doctors}

The doctors answered several questions about their health at the time of filling in the questionnaire (table 3). Almost 4 out of 10 found their own health to be very good at that moment $(37.8 \%)$. Immediately after the procedure, the self-reported impact of the disciplinary process on the self-perceived health of doctors was on average 5.0 for the whole population (not in table). The differences between doctors receiving reprimands (5.8) and warnings (4.8) were not significant. As time passed, the perceived effect of the procedure on health diminished (a mean of 1.7 for the whole group at moment of filling out the questionnaire). The difference between the doctors receiving reprimands (2.1) and warnings (1.6) continued to exist. Differences in the impact between respondents whose judgement was issued up to 1 year ago and $>1$ year ago were not significant (not in table). As we have no information on the health of professionals prior to the procedure, the perceived change in health directly after the 
Table 3 Percentage of respondents who reported specific health complaints, for doctors given a reprimand $(n=42-45)$ and doctors given a warning $(n=164)^{*}$

\begin{tabular}{lllll}
\hline & Reprimand, $\%$ & Warning, $\%$ & Total, $\%$ & $\mathbf{X}^{\mathbf{2}}$ ( $\mathbf{p}$ value) \\
\hline General health status & & & & - \\
Poor or very poor & 2.2 & 1.2 & 1.4 & \\
Okay & 6.7 & 7.3 & 7.2 & \\
Well & 51.1 & 54.3 & 53.6 & \\
Very good & 40 & 37.2 & 37.8 & - \\
Depressive complaints (>9 on PHQ-9) & 7.1 & 2.6 & 3.6 & - \\
Anxiety complaints (>9 on GAD-7) & 2.3 & 1.9 & 2.0 & - \\
$\begin{array}{l}\text { Burnout (>3.2 on NEA questions) } \\
\text { Work absence in the last 12 months (one or } \\
\text { more times) }\end{array}$ & 5.4 & 12.2 & 10.8 & 3.93 (0.047) \\
\hline
\end{tabular}

*Only significant differences are given.

Bolded value considered differences to be significant where they had a $p$ value of $<0.05$.

GAD-7, Generalised Anxiety Disorder scale; NEA, National Survey of Working Conditions; PHQ-9, Patient Health Questionnaire.

procedure and after the passing of time can be due to other circumstances.

A small percentage of respondents reported moderate-to-severe depressive complaints $(3.6 \%)$, moderate-to-severe anxiety disorder $(2 \%)$ or indications of burnout $(10.8 \%)$.

\section{Impact on professional practice}

The majority of doctors reported the disciplinary process had a negative impact on their professional practice; $71.1 \%$ of doctors given a reprimand indicated that the procedure only had a negative impact. Among doctors receiving warnings, this was significantly less, at $40.8 \%$ $\left(\mathrm{p}=0.004, \mathrm{X}^{2}=13.19\right) ; 4.4 \%$ of doctors given a reprimand and $8.5 \%$ of doctors given a warning indicated that the procedure only had a positive impact (not in table).

Respondents reported various changes in their professional practice that are obviously negative (table 4): avoiding high-risk patients $(47.5 \%$ with a reprimand vs $38.2 \%$ with a warning), seeing each patient as a new complainant $(41.4 \%$ vs $35.2 \%)$ and avoiding similar patients as the complainant $(41.4 \%$ vs $29 \%)$. Some changes can be perceived as positive, such as making more accurate notes in patients' files (64.2\%) and discussing improvement measures with their colleagues and/or supervisor $(60.8 \%)$ more often since the disciplinary procedure. Some reported changes can be either positive

Table 4 Percentage of doctors who agree or totally agree with statements about changes in their professional practice due to the disciplinary procedure for doctors given a reprimand $(n=53-61)$ and doctors given a warning $(n=174-191)^{*}$

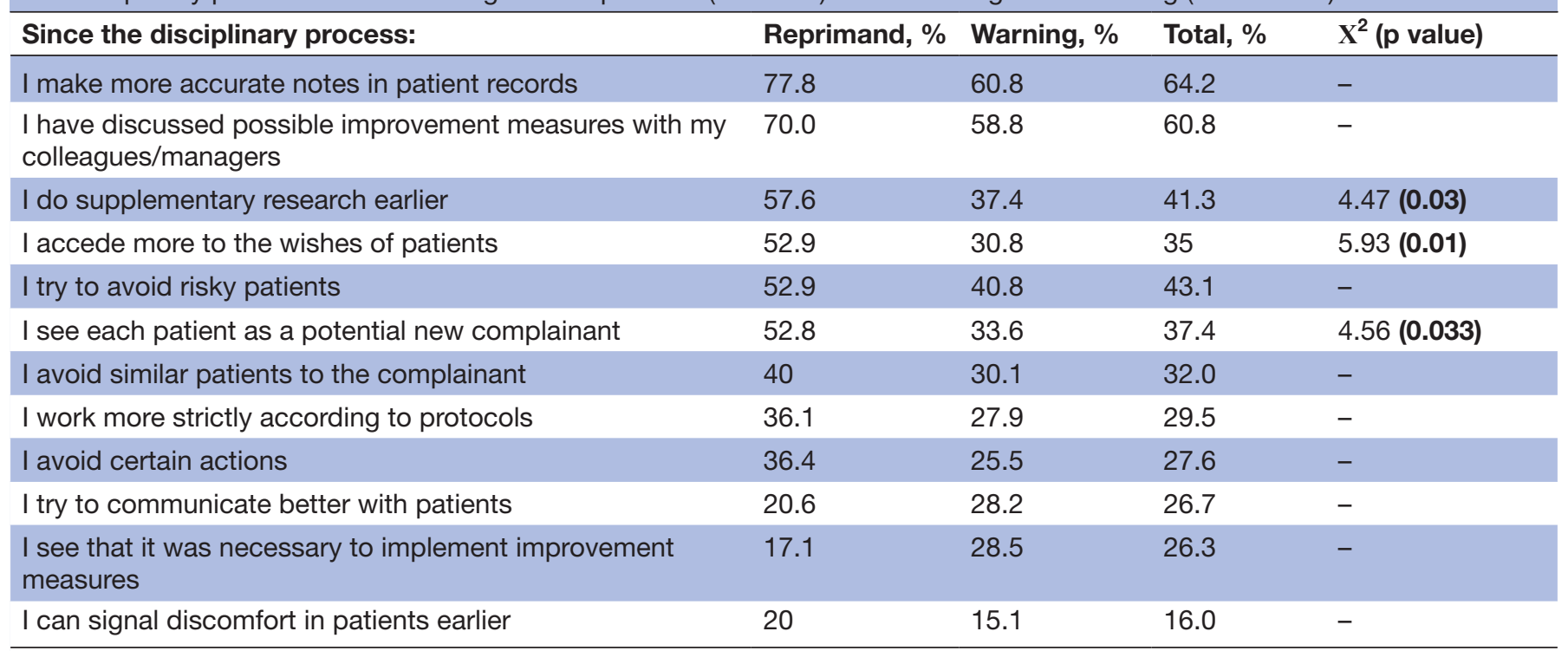

*Only significant differences are given.

Bolded value considered differences to be significant where they had a $p$ value of $<0.05$. 
Table 5 Percentage of respondents who reported consequences for their business or finances and career opportunities from the disciplinary process for doctors given reprimands $(n=33-81)$ and warnings $(n=151-212)^{*}$

\begin{tabular}{|c|c|c|c|c|}
\hline & Reprimand, \% & Warning, $\%$ & Total, \% & $X^{2}$ (p value) \\
\hline Lost patients & & & & $19.75(\mathbf{0 . 0 0 0})$ \\
\hline Yes & 28.9 & 9.8 & 13.9 & \\
\hline No & 47.8 & 72.4 & 64.9 & \\
\hline I do not know & 22.2 & 11.7 & 13.9 & \\
\hline Not Applicable (N/A) & 11.1 & 6.1 & 7.1 & \\
\hline Fewer new patients & & & & 15.07 (0.002) \\
\hline Yes & 13.5 & 2.7 & 4.8 & \\
\hline No & 56.8 & 82.5 & 77.4 & \\
\hline I do not know & 24.3 & 9.4 & 12.4 & \\
\hline $\mathrm{N} / \mathrm{A}$ & 5.4 & 5.4 & 5.4 & \\
\hline $\begin{array}{l}\text { Colleagues who do not want to collaborate or do not } \\
\text { want to refer patients to them }\end{array}$ & & & & $8.55(0.036)$ \\
\hline Yes & 0 & 2.7 & 2.2 & \\
\hline No & 75.7 & 89.2 & 86.5 & \\
\hline I do not know & 21.6 & 7.4 & 10.3 & \\
\hline N/A & 2.7 & 0.7 & 1.1 & \\
\hline Consequences for career opportunities & & & & $20.3(0.000)$ \\
\hline Yes & 33.3 & 7.6 & 13.2 & \\
\hline No & 66.6 & 92.4 & 86.8 & \\
\hline
\end{tabular}

*Only significant differences are given.

Bolded value considered differences to be significant where they had a $p$ value of $<0.05$.

or negative according to context, but are commonly associated with defensive medicine, such as complying to patient's wishes more and doing more supplementary research.

There are significant differences between doctors given a reprimand and doctors given a warning on three items: seeing each patient as a potential new complainant $(52.8 \%$ vs $33.6 \%)$, doing supplementary research earlier (57.6\% vs $37.4 \%$ ) and complying more with the wishes of patients $(52.9 \%$ vs $30.8 \%$ ) (table 4 ).

\section{Consequences for business/finances and career opportunities}

Doctors were asked about various consequences on their business or finances of their involvement in a disciplinary process (table 5) with the option to supply further explanation when answering 'yes'. Doctors given reprimands reported more negative consequences than doctors given warnings. These differences were significant for loss of patients $(\mathrm{p}=0.000)$, fewer new patients $(\mathrm{p}=0.002)$, colleagues who no longer want to work with them or refer patients to them $(\mathrm{p}=0.036)$ and consequences for career opportunities $(\mathrm{p}=0.000)$ since the disciplinary procedure.

\section{DISCUSSION}

\section{The Dutch disciplinary system and transparency}

The Dutch disciplinary system aims at quality improvement by correcting and, in severe cases restricting, professionals' behaviour. Disciplinary case law is published anonymously and is part of the Dutch professional standard for healthcare professionals, prescribing desired behaviour in specific circumstances in order to learn from others' mistakes. Since July 2012 the names of doctors given reprimands, a disciplinary measure imposed for behaviour that was incorrect, yet not reason enough to restrict practice, were disclosed online and in print to provide the public with quality information. From the onset this policy has led to debate between politicians, patient representatives and doctors' associations, the first desiring maximum transparency, the latter claiming a culture of 'naming and shaming'. ${ }^{25} 26$

The call for transparency is often driven by a political response to high-profile scandals ${ }^{27} 28$ and can be understood as a policy measure for enhancing public accountability and legitimacy of governmental institutions. Although transparency is commonly assumed to be a good thing, it can leave unintended damage in its wake. This study aimed to assess doctors' experiences with the disciplinary procedure and whether reprimanded doctors whose measure was disclosed perceived an extra impact on their welfare, personal life and professional functioning, beyond the impact of the measure itself. A questionnaire was submitted to doctors who received a warning or reprimand from a disciplinary board. Until recently, all reprimands were disclosed to the public in 
the Netherlands. In April 2018, a majority in the Dutch House of Representatives voted against disclosure of reprimands, leaving disclosure of reprimands a discretion of the disciplinary board when deemed appropriate or necessary.

\section{Adverse consequences of disciplinary procedures}

This study shows that disciplinary procedures are often a taxing experience for doctors, who perceive the procedure and its consequences predominantly negative. Respondents reported emotions such as feeling under attack, powerless, angry and criminalised. We found some impact on physical and mental health, confirming the results of previous studies on the effect of medicolegal procedures on doctors' health and functioning ${ }^{10} 14$ 29-34 but the effect we found was relatively small compared with some other studies, such as by Bourne et al. ${ }^{10}$

Besides negative effects, the responding doctors also reported positive changes, such as making more accurate notes in patient records and discussing improvement measures with colleagues. This confirms results from the study by Plews-Ogan $e t$ al, that doctors are willing to learn from their mistakes and possibly become better doctors because of it. ${ }^{35}$ Nevertheless, learning currently comes at a high price, as the majority of doctors experienced the disciplinary procedure as having a negative impact on their health and on their professional functioning and business.

For several outcomes it was clear that the perceived impact was greater compared with doctors given warnings (which are not disclosed). Public disclosure also clearly led to consequences for practice, such as losing patients, getting fewer new patients and obstruction of career opportunities since the disciplinary procedure. For the latter category, examples given were not being able to get a new job or getting questioned about the reprimand by the health insurer. It is important to note these consequences are most likely due to disclosure of the reprimand. Unless the case has received a lot of media attention, health insurers and patients are unlikely to know about reprimands otherwise.

Since the Dutch disciplinary system is aimed at maintaining quality of healthcare, well-being of doctors during and after disciplinary procedures should be high at the patient safety agenda. In a study regarding the consequences of malpractice lawsuits, Balch $e t$ al state it is difficult to determine the 'direction of effect', that is, our data can also be explained such that mental issues led to suboptimal healthcare, leading to a complaint to a disciplinary board, with more severe mental issues resulting in a reprimand instead of a warning. Similarly, we are careful not to jump to conclusions regarding the impact of disciplinary procedures on (mental) health.

However, West et al reported a link between doctors' distress and subsequent self-reported errors, suggesting a vicious cycle, whereby medical errors may lead to personal distress, which then contributes to further deficits in patient care. ${ }^{36}$ This association between distress among doctors with perceived medical errors and decreased empathy and compassion for patients, negatively affecting the quality of care, supports the reasoning that complaints procedures that aim to increase the quality of care may in fact have a counterproductive effect.

\section{The second victim}

The results of this study are even more significant in the light of a growing awareness of the impact that experiencing a patient safety incident can have on healthcare professionals. ${ }^{6}$ Healthcare professionals can be traumatised by the event itself, reactions of patients and their families or comments from colleagues. Wu et at and Steckelberg ${ }^{6}$ recommend supporting doctors who made mistakes. ${ }^{56}$ This support is best provided by peers, or by a mentor or supervisor. Without this kind of support, many doctors do not discuss their errors with colleagues because they cannot identify physicians who are supportive listeners. ${ }^{37}$ In the Netherlands as elsewhere support programmes have been developed. ${ }^{38}$ It has been demonstrated that supporting doctors leads to better quality of care. ${ }^{3}$

\section{Patient satisfaction}

The patient who makes the complaint does not have a formal stake in the disciplinary procedure and thus disciplinary law does not seek to fulfil the needs of the patient who makes the complaint. However, in light of the results of this study it is important to keep in mind research into patient satisfaction with Dutch complaint procedures revealed only half of complaining patients report satisfaction with the disciplinary procedure. This is most likely due to a reported lack of confidence that the disciplinary procedure will change or improve healthcare. ${ }^{39}$ This leads us to the conclusion that the disciplinary process in the Netherlands is at odds with scientific consensus that nurturing a culture of support, in contrast to naming and blaming, aids learning and is beneficial to patients and doctors alike. If we weigh the importance of transparency against the negative consequences of disclosing measures for doctors, does the scale tip in favour of transparency?

\section{CONCLUSION}

Procedures and rules to guarantee quality of care must exist. However, besides some positive consequences for quality of care, disciplinary law seems to have several negative side effects on health, professional functioning and business or financial consequences for doctors that outweigh the positive consequences. Disclosing the disciplinary measures does not seem to benefit the quality of healthcare.

A system that leads to doctors who are distressed and display behaviour that is associated with defensive medicine, such as avoiding certain patients and doing possibly unnecessary supplementary research, is not efficient, does not necessarily lead to better healthcare for patients and leads to higher healthcare costs for society. This may be 
counterproductive to the pursuit of the primary purpose of disciplinary law: improving the quality of professional practice by standardisation and by correction of individual doctors. Supporting doctors after complaints and patient safety incidents, enabling them to learn from mistakes and aid them in disclosure, should be systematically embedded to ensure doctors' and patients' best interests.

\section{LIMITATIONS}

The study sample was not large, but the numbers were sufficient for the statistical analyses.

In order to study the phenomenon of disclosure of disciplinary measures and the experiences with it, this was the best feasible design. Still, the two groups of professionals with disciplinary measures (warning and reprimand) may not be comparable because of the context and nature of the complaint and the related culpability and judgement of the disciplinary court.

Reported (mental) health issues could have been a result, or an underlying cause of complaints. The bigger the health issues, the heavier the measure and hence the disclosure of the measure, one might reason. Respondents also might experience the measure as heavier precisely because it is publicly disclosed. Furthermore, the relationship between the measure and the outcome variables has not been analysed, but the results are self-reported by the respondents. This may be rather subjective. Therefore, a causal relationship between the disciplinary procedure and the outcome variables, or disclosure of the measure and the outcome variables cannot be proven.

The response rate was moderate, which may have caused a non-response bias. Non-response analysis was not possible because no characteristics of the non-respondents are available, in part due to meticulous privacy regulations. All letters were sent by the disciplinary board; the doctors remained anonymous to the researchers. It was stressed that people were entirely free to decide whether or not to complete the questionnaire and they could return the questionnaire to the researchers anonymously. The researchers had no information about non-responders. An important reason for the non-response could be that filing in the questionnaire made respondents uncomfortable because it revived the situation that the complaint was about. Another reason could be that the disciplinary procedure was already a great burden, making people reluctant to participate.

Consequences of the moderate response rate could be that the study population is not representative to the entire group of doctors who received a disciplinary measure. Possibly, a specific group of disciplined doctors, for instance, those who feel more empowered, may have responded to our questionnaire.

The study population was not comparable to the Dutch population of doctors in terms of age and gender. It is unclear why the percentage of males is so high in the study population. The fact that the study population is older compared with the Dutch population can be explained by the fact that the older the doctor is, the more chance there is that they will ever have a complaint filed against them.

Complaint and disciplinary procedures differ between jurisdictions, possibly influencing the severity of the perceived impact. Results should be generalised with caution, taking the specifics of Dutch disciplinary law in consideration when doing so.

This study reveals valuable information about doctors who experience disciplinary consequences. With its limitations, we believe this is an important addition to the existing body of research.

\section{Author affiliations}

${ }^{1}$ Faculty of Law, Vrije Universiteit Amsterdam, Amsterdam, The Netherlands ${ }^{2}$ NIVEL, Netherlands institute for health services research, Utrecht, The Netherlands ${ }^{3}$ Reinier van Arkelgroep, s-Hertogenbosch, The Netherlands

Acknowledgements The authors would like to thank the people who submitted a questionnaire for their cooperation.

Contributors BL, RB, AJEdV and RF participated in the design of the study. RB and $\mathrm{MH}$ analysed and interpreted the data. All authors helped to draft the manuscript. All authors critically revised and approved the final manuscript. All authors agreed to be personally accountable for the author's own contributions and for ensuring that questions related to the accuracy or integrity of any part of the work, even ones in which the author was not personally involved, are appropriately investigated, resolved and documented in the literature.

Funding This study was funded by the Dutch Ministry of Health, Welfare and Sports.

Competing interests None declared.

Patient consent for publication Not required.

Ethics approval As all the research participants were competent individuals and no participants were subjected to any interventions or actions, no ethical approval was needed under Dutch law on medical research (Medical Research Involving Human Subjects Act).

Provenance and peer review Not commissioned; externally peer reviewed. Data sharing statement Extra data are available by emailing RB: r.bouwman@ nivel.nl.

Open access This is an open access article distributed in accordance with the Creative Commons Attribution Non Commercial (CC BY-NC 4.0) license, which permits others to distribute, remix, adapt, build upon this work non-commercially, and license their derivative works on different terms, provided the original work is properly cited, appropriate credit is given, any changes made indicated, and the use is non-commercial. See: http://creativecommons.org/licenses/by-nc/4.0/.

\section{REFERENCES}

1. de Wit ME, Marks CM, Natterman JP, et al. Supporting second victims of patient safety events: shouldn't these communications be covered by legal privilege? J Law Med Ethics 2013;41:852-8.

2. Edrees $\mathrm{HH}$, Paine LA, Feroli ER, et al. Health care workers as second victims of medical errors. Pol Arch Med Wewn 2011;121:101-8.

3. Seys D, Scott S, Wu A, et al. Supporting involved health care professionals (second victims) following an adverse health event: a literature review. Int J Nurs Stud 2013;50:678-87.

4. Seys D, Wu AW, Van Gerven E, et al. Health care professionals as second victims after adverse events: a systematic review. Eval Health Prof 2013;36:135-62.

5. Wu AW. Medical error: the second victim. The doctor who makes the mistake needs help too. BMJ 2000;320:726.

6. Wu AW, Steckelberg RC. Medical error, incident investigation and the second victim: doing better but feeling worse? BMJ Qual Saf 2012;21:267-70.

7. Scott SD, Hirschinger LE, Cox KR, et al. Caring for our own: deploying a systemwide second victim rapid response team. Jt Comm J Qual Patient Saf 2010;36:233-40. 
8. Coughlan B, Powell D, Higgins MF. The second victim: a review. Eur J Obstet Gynecol Reprod Biol 2017;213:11-16.

9. Robertson JJ, Long B. Suffering in silence: medical error and its impact on health care providers. J Emerg Med 2018:54:402-9.

10. Bourne T, Wynants L, Peters M, et al. The impact of complaints procedures on the welfare, health and clinical practise of 7926 doctors in the UK: a cross-sectional survey. BMJ Open 2015;5:e006687.

11. Bruers JJM, et al. Het welbevinden van tandartsen na een klachtenprocedure. Ned Tijdschr Tandheelkd 2015;122:41-8.

12. Cunningham $\mathrm{W}$, Wilson $\mathrm{H}$. Complaints, shame and defensive medicine. Quality and Safety in Health Care 2011.

13. Verhoef LM, Weenink JW, Winters S, et al. The disciplined healthcare professional: a qualitative interview study on the impact of the disciplinary process and imposed measures in the Netherlands. BMJ Open 2015;5:e009275.

14. Bourne T, Vanderhaegen J, Vranken R, et al. Doctors' experiences and their perception of the most stressful aspects of complaints processes in the UK: an analysis of qualitative survey data. BMJ Open 2016;6:e011711.

15. Panella M, Rinaldi C, Vanhaecht K, et al. [Second victims of medical errors: a systematic review of the literature]. Ig Sanita Pubbl 2014;70:9-28.

16. Studdert DM, Mello MM, Sage WM, et al. Defensive medicine among high-risk specialist physicians in a volatile malpractice environment. JAMA 2005;293:2609-17.

17. Assing Hvidt E, Lykkegaard J, Pedersen LB, et al. How is defensive medicine understood and experienced in a primary care setting? A qualitative focus group study among Danish general practitioners. BMJ Open 2017;7:e019851.

18. Reschovsky JD, Reschovsky JD, Mello MM, et al. Physicians' fears of malpractice lawsuits are not assuaged by tort reforms. Health Aff 2010;29:1585-92.

19. Gallagher TH, Waterman AD, Ebers AG, et al. Patients' and physicians' attitudes regarding the disclosure of medical errors. JAMA 2003;289:1001-7.

20. Kaldjian LC, Jones EW, Rosenthal GE. Facilitating and impeding factors for physicians' error disclosure: a structured literature review. Jt Comm J Qual Patient Saf 2006;32:188-98.

21. Den Haag. Toezicht., T.v.d.g.e.C.v.M., Jaarverslag 2015. 2015.

22. Hooftman WE MG, Janssen B, de Vroome EMM, et al. Methodologie en globale resultaten. Leiden, Heerlen: TNO/CBS, 2016.

23. Alhafaji Y, Frederiks B, Legemaate J. Legemaate, Ervaringen van klagers en aangeklaagde artsen met het tuchtrecht [Experiences of complainants and accused doctors with the Disciplinary System]. Nederlands-Vlaams tijdschrift voor Mediation en conflictmanagement. 2009;13.

24. CBS. CBS Statline. 2015.

25. KNMG. KNMG pleit voor afschaffen 'naming and shaming. 2017 https://www.knmg.nl/actualiteit-opinie/nieuws/nieuwsbericht/knmgpleit-voor-afschaffen-naming-and-shaming.htm

26. Patiëntenfederatie Nederland. Berispingen en boetes voor artsen moeten openbaar blijven. 2017 https://www.patientenfederatie. $\mathrm{nl} /$ nieuws/berispingen-en-boetes-voor-artsen-moeten-openbaarblijven-2

27. Runciman WB, Merry AF, Tito F. Error, blame, and the law in health care--an antipodean perspective. Ann Intern Med 2003;138:974-9.

28. Duckett SJ, Collins J, Kamp M, et al. An improvement focus in public reporting: the Queensland approach. Med J Aust 2008;189(1112):616-7.

29. Nash L, Walton M, Daly M, et al. GPs' concerns about medicolegal issues - How it affects their practice. Aust Fam Physician 2009;38:66.

30. Nash LM, Walton MM, Daly MG, et al. Perceived practice change in Australian doctors as a result of medicolegal concerns. Med $J$ Aust 2010;193:579-83.

31. Balch CM, Oreskovich MR, Dyrbye LN, et al. Personal consequences of malpractice lawsuits on American surgeons. J Am Coll Surg 2011;213:657-67.

32. Charles SC, Wilbert JR, Kennedy EC. Physicians' self-reports of reactions to malpractice litigation. Am J Psychiatry 1984;141:563-5.

33. Ryll NA. Living through litigation: malpractice stress syndrome. $J$ Radiol Nurs 2015;34:35-8.

34. Fileni A, Magnavita N, Mammi F, et al. Malpractice stress syndrome in radiologists and radiotherapists: perceived causes and consequences. Radiol Med 2007;112:1069-84.

35. Plews-Ogan M, May N, Owens $\mathrm{J}$, et al. Wisdom in medicine: what helps physicians after a medical error? Acad Med 2016;91:233-41.

36. West CP, Huschka MM, Novotny PJ, et al. Association of perceived medical errors with resident distress and empathy: a prospective longitudinal study. JAMA 2006;296:1071-8.

37. Kaldjian LC, Forman-Hoffman VL, Jones EW, et al. Do faculty and resident physicians discuss their medical errors? J Med Ethics 2008;34:717-22

38. Pratt S, Kenney L, Scott SD, et al. How to develop a second victim support program: a toolkit for health care organizations. Jt Comm J Qual Patient Saf 2012;38:235-40.

39. Friele RD, Kruikemeier S, Rademakers JJ, et al. Comparing the outcome of two different procedures to handle complaints from a patient's perspective. J Forensic Leg Med 2013;20:290-5

40. Hout E, Friele R, Legemaate J. De burger als klager in het tuchtrecht voor de gezondheidszorg. Weinig klachten, mogelijk door geringe kennis van tuchtrechtsysteem. Ned Tijdschr Geneeskd 2009;153:A548.

41. Laarman B, Akkermans AJ. Compensation schemes for damage caused by healthcare and alternatives to court proceedings in the Netherlands - the Netherlands National Report to the 20th General Congress of the International Academy of Comparative Law, Fukuoka, Japan, 22-28 July 2018. SSRN Electronic Journal 2018.

42. Hirschman A. Exit, voice, and loyalty; responses to decline in Firms, Organizations, and States. Cambridge: MA: Harvard UP, 1970.

43. Enthoven AC, van de Ven WP. Going Dutch--managed-competition health insurance in the Netherlands. N Engl J Med 2007;357:2421-3.

44. de Vries H, Sanderson P, Janta B, et al. International comparison of ten medical regulatory systems. 2009.

45. Borow M, Levi B, Glekin M. Regulatory tasks of national medical associations - international comparison and the Israeli case. Isr J Health Policy Res 2013;2:8. 